\title{
Impulsiveness of Different Sociometric Groups among Secondary School Students
}

\author{
Shafeeqa bano ${ }^{1}$
}

\section{ABSTRACT}

The present study aimed at investigating "Impulsiveness of different sociometric groups among secondary school students". Initially the sample consisted of 2000 secondary school students (girls) of Aligarh district. After that through simple random sampling, four sociometric categories i.e., Populars(100), Neglectees(100), isolates(100) and rejectees(100) were drawn and taken as the final research subject. The test developed by Sharma (1970) was used for drawing sociometric categories. To study Impulsiveness among these sociometric categories, the scale developed by Rai \& Sharma(1988) was used. The finding of the research indicated that no Significant difference was found among four Sociometric groups ( i.e., populars, neglectees, isolates, \& rejectees)" and between the two sociometric groups i.e., populars \& neglectees, populars \& isolates, populars \& rejectees, neglectees \& isolates, neglectees \& rejectees, isolates $\&$ rejectees on the variable of impulsiveness.

Keywords: Impulsiveness, Sociometric groups, Secondary school students

The tendency to join with others in groups is perhaps the single most important characteristic of humans, and the process that unfold within these groups leave an indelible imprint on their members and on the society (Forsyth, 2006). The term sociometry is coined by Moreno (1934). Sociometry is a measure of assessing the attractions and repulsions within a given group. Different sociometric groups include populars, above average, average, below average, neglectees, rejectees and isolates. The process of socialization and social interaction is expected to produce personalities that are substantially integrated and consistent. The emergence of integrated personalities, leads towards adjustment and harmonious social relation. This is the intended consequence of socialization and it is evident that it occurs in substantial measures. The general pattern of socialization is the same in all cases, however, actual experience tend to vary from situation to situation and from individual to individual. When individual is in the society and he interacts in it, there are chances of his being accepted as a leader, and there equally chances for him to accept the role of the follower (Malik, 1978 ).

${ }^{1} \mathrm{PhD}$ scholor, department of education A.M.U.Aligrah(U.P)

(C) 2015 I S bano; licensee IJIP. This is an Open Access Research distributed under the terms of the Creative Commons Attribution License (http://creativecommons.org/licenses/by/2.0), which permits unrestricted use, distribution, and reproduction in any Medium, provided the original work is properly cited. 


\section{Impulsiveness of Different Sociometric Groups among Secondary School Students}

Impulsiveness is a personality trait which includes quick and impulsive behaviour, risk taking activities, lack of emotional control, non-planning, liveliness and hyper activity. (Barratt, 1965) \& (Eysenck \& Eysenck, 1977). Impulsivity typically refers to "behaviour that incorporates a component of rashness, lack of foresight or planning or as a behaviour that occurs without reflection or careful deliberation.” According to (Barratt 1994; Eysenck et.al., 1985; Parker \& Bagby, 1997), impulsivity is defined as the extent to which individuals are unable to control their thoughts and behaviours.

According to Corsini(1999) 'Impulsiveness' is a type of behaviour characterized by the inclination of an individual to act on impulse rather than thoughts. In general, Impulsivity refers to quick, unplanned behaviour that appear due to the lack of clear forethought.

Impulsiveness in the present study may be defined as the total score obtained by secondary school students on the scale of Impulsiveness (IS) prepared by the Rai and Sharma (1988).

\section{OBJECTIVES OF THE STUDY}

Following are the main objectives of the study.

- To find out difference, if any, on the variable of Impulsiveness among four Sociometric groups (viz., populars, neglectees, isolates \& rejectees).

- To make the comparison between two Sociometric groups (i.e., populars \& neglectees, populars \& isolates, populars \& rejectees, neglectees \& isolates, neglectees \& rejectees, isolates \& rejectees) on the variable of Impulsiveness.

\section{HYPOTHESES OF THE STUDY}

In order to achieve the above objectives following hypotheses are undertaken in this investigation

- There will be statistically significant difference among the four Sociometric groups (i.e populars, neglectees, isolates, \& rejectees) on the variable of Impulsiveness.

- Significant difference will be found on the variable of Impulsiveness between two Sociometric groups. (i.e., populars \& neglectees, populars \& rejectees, populars \& isolates, neglectees \& isolates, neglectees \& rejectees, isolates \& rejectees). 


\section{REVIEW OF THE RELATED STUDIES}

Impulsivity has been investigated as a predictor of aggressive behaviour and has been suggested as a mediator of the sex difference in direct aggression (Campbell, 2006; Strüber, Luck, \& Roth, 2008). Some forms of impulsivity are more strongly implicated in aggressive behaviour than others. A review by Campbell (2006) suggested that cognitive forms of impulsivity were less likely candidates for explaining sex differences in aggression than more affective forms.

Parren, et.al. (2006) studied on Swiss kindergartners children's and adults (combined) reported that high impulsivity/ inattention were related to sociometric rejection, but not acceptance.

Wilson (2006) found that children who were labeled by their peers as aggressive-rejected were more impulsive than non-aggressive popular children and made more inappropriate attempts at engaging in social interactions with their classmates than non aggressive popular children.

Poulin \& Dishion ( 2008) Studied methodological issues in the use of peer sociometric nominations with middle school youth. Participants were 664 sixth graders from three middle schools. Peer nominations for sociometric items (i.e., like most and like least), as well as teacher ratings of antisocial behavior and records of academic performance, were collected. A sequence effect in peer nominations was found. Results also indicated that the nominations received from the other-sex grade mates and from the grade mates outside the classroom improved the predictive validity of the sociometric measure.

Wallien, et.al. (2009) conducted a sociometric study on peer group status of gender dysphoric children, the social position of gender-referred children in a naturalistic environment. Peer nomination technique to examine their social position in the class was used. A total of 28 children (14 boys and 14 girls), referred to a gender identity clinic, and their classmates $(n=495)$ were included. Results showed that the gender-referred children had a peer network of children of the opposite sex. The social position of gender-referred boys was less favorable than that of gender-referred girls.

Lorenzo-Chávez et.al. (2011) investigated whether peer nominations of social behaviour and teacher ratings of adjustment varied by chronic and non-chronic peer rejection (sociometric status) in 188 Cuban elementary school children. Data were collected through questionnaires administered at schools in several parts of Cuba. Rejected children at year one had significantly 
higher scores on peer nominations for withdrawal and aggression. Rejected students also scored higher on impulsivity than other sociometric groups. They also had higher teacher ratings on externalizing and problem behaviours and lower scores on cooperation. In general, the implications for maladjustment were not substantially greater for being rejected by peers two years in a row than for being rejected at only one point in time.

\section{STATEMENT OF THE PROBLEM}

"Study of impulsiveness of different sociometric groups among secondary school students"

\section{METHODOLOGY}

Impulsiveness Scale (IS) developed by Rai and Sharma (1988) and socimetric scale developed by sharma(1970) were used on the secondary school students(girls) of Aligarh District in order to measure their impulsiveness.

\section{Sample}

Initially the sample consisted of 2000 secondary school students (girls) of Aligarh district. After that through simple random sampling four sociometric categories i.e., Populars(100), Neglectees(100), isolates(100) and rejectees(100) were drawn and taken as the final research subject.

\section{Description of the Tests Used}

For drawing sociometric categories the test developed by Sharma (1970) was used. Following questions are included in the sociometric questionnaire, used in the present study.

1. If you are asked to shift in some other class, to whom three students of your class would you like to take with you?

2. Which three students of your class would you like to play with during interval or recess?

3. You would have wanted to do some activities of your choice. With whom three Students of your class would you like to do these activities?

4. Name any one student of your class with whom you would not like to do any activity.

For the study of Impulsiveness, the scale developed by Rai and Sharma(1988) was used. This scale contains 30 items and the responses obtained in the form of tick marks $(\sqrt{ })$ on 30 items of scale. Each item of the scale contained two alternative responses. The response indicating impulsiveness was scored as 1 and response indicating no impulsiveness was scored as 0 . The 
reliability co-efficient of $\mathbf{0 . 7 2}$ was found. For the present scale, The validity was found to be 0.58 .

In order to analyze and interpret the data, the following suitable techniques have been employed.

1. SOCIOGRAM

2. MEAN Rejectees Sociogram

3. F-RATIO

4. t-TEST

5. CORRELATION

The collected data was analysed by using SPSS version 16.

\section{ANALYSIS AND INTERPRETATION}

Analysis of variance for different Sociometric groups on the variable of Impulsiveness

Hypothesis- 1. "There will be statistically significant difference among the four sociometric groups (i.e populars, neglectees, isolates, \& rejectees), on the variable of Impulsiveness.”

To verify hypothesis no.1 F-test was applied to obtain a global picture as to whether there is any significant difference on the variable of Impulsiveness among four Sociometric groups.

The F-value of Impulsiveness among four Sociometric groups is given in table- 1

TABLE 1, SUMMARY TABLE OF ANALYSIS OF VARIANCE FOR DIFFERENT SOCIOMETRIC GROUPS ON THE VARIABLE OF IMPULSIVENESS

\section{SOURCE OF VARIANCE SUM OF SQUARES DF MEAN SQUARES F-RATIO}

\begin{tabular}{|c|c|c|c|c|}
\hline TOTAL & 5487.94 & 399 & & \\
\hline BETWEEN CONDITIONS & 40.57 & 3 & \multicolumn{2}{|l|}{13.52} \\
\hline WITHIN CONDITION & 5447.37 & 396 & \multicolumn{2}{|l|}{13.76} \\
\hline & & & \multicolumn{2}{|r|}{$0.98^{\mathrm{NS}}$} \\
\hline
\end{tabular}

NS= Not Significant 
Table 1 shows that the F-ratio for Impulsiveness is 0.98, which is not significant even at 0.05 level of confidence. This reveals that there exists no significant difference among various sociometric groups, i.e. populars, neglectees, isolates, and rejectees in relation to their impulsiveness. Hence, the first hypothesis i.e., "There will be statistically significant difference among the four Sociometric groups (i.e., populars, neglectees, isolates, \&rejectees), on the variable of Impulsiveness" is rejected.

Comparison between two Sociometric groups (i.e., populars \& neglectees, populars \& isolates, populars \& rejectees, neglectees \& isolates, neglectees \& rejectees, isolates \& rejectees) on the variable of Impulsiveness".

Hypothesis-2. Significant difference will be found on the variable of Impulsiveness between two sociometric groups. (i.e., populars \& neglectees, populars \& rejectees, populars \& isolates, neglectees \& isolates, neglectees \& rejectees, isolates \& rejectees).

In order to compare the two groups i.e. populars \& neglectees, populars \& isolates, populars \& rejectees, neglectees \& isolates, neglectees \& rejectees, isolates \& rejectees, on the variable of Impulsiveness, ' $t$ '-test was applied. The mean scores, S.D. was found out and ' $t$ '-value was calculated. The ' $t$ '-values, mean scores and S.D. of different Sociometric groups are given in table 2 and 3 respectively.

TABLE- 2, 't'-VALUE FOR DIFFERENT SOCIOMETRIC GROUPS ON THE VARIABLE OF IMPULSIVENESS

\begin{tabular}{|c|l|c|c|c|c|}
\hline $\begin{array}{c}\text { S. } \\
\text { No. }\end{array}$ & \multicolumn{1}{|c|}{ Between Group } & df & $\begin{array}{c}\text { 't'- } \\
\text { value }\end{array}$ & $\begin{array}{c}\text { Level of } \\
\text { significance }\end{array}$ & Remark \\
\hline 1. & $1 \& 2$ (POPULARS \& NEGLECTEES) & 198 & 0.81 & - & N.S. \\
\hline 2. & $1 \& 3$ (POPULARS \& ISOLATES) & 198 & 0.46 & - & N.S. \\
\hline 3. & $1 \& 4$ (POPULARS \& REJECTEES) & 198 & 0.77 & - & N.S. \\
\hline 4. & $2 \& 3$ (NEGLECTEES \& ISOLATES) & 198 & 1.34 & - & N.S. \\
\hline 5. & $2 \& 4$ (NEGLECTEES \& REJECTEES) & 198 & 1.62 & - & N.S. \\
\hline 6. & $3 \& 4$ (ISOLATES \& REJECTEES) & 198 & 0.35 & - & N.S. \\
\hline
\end{tabular}

N.S. = Not significant 
Having a look on table, t-values of the total scores of Impulsiveness is not found significant for all the pairs of groups i.e. between group1 and group2 (populars \& neglectees), group1 and group3 (populars \& isolates),group1 and group4 (populars \& rejectees),group2 and group3 (neglectees \& isolates),group2 and group4 (neglectees \& rejectees), group3 and group4 (isolates $\&$ rejectees), as the obtained t-value between populars $\&$ neglectees is 0.81 , populars \& isolates is 0.46 , populars $\&$ rejectees is 0.77 , neglectees $\&$ isolates is 1.34 , neglectees \& rejectees is 1.62 and isolates $\&$ rejectees is 0.35 , are not significant even at 0.05 level of confidence. Hence no two group differ each other.

TABLE-3, MEAN SCORES OF POPULARS, NEGLECTEES, ISOLATES AND REJECTEES ON THE VARIABLE OF IMPULSIVENESS

\begin{tabular}{|c|c|c|c|c|c|c|}
\hline S.No. & Groups & N & Mean & $\begin{array}{c}\text { Percentage } \\
\text { Mean }\end{array}$ & S.D. & $\begin{array}{c}\text { Percentage } \\
\text { S.D. }\end{array}$ \\
\hline 1. & Populars & 100 & 12.63 & 42.10 & 3.92 & 13.06 \\
\hline 2. & Neglectees & 100 & 12.20 & 40.66 & 3.60 & 12.01 \\
\hline 3. & Isolates & 100 & 12.87 & 42.90 & 3.47 & 11.59 \\
\hline 4. & Rejectees & 100 & 13.05 & 43.50 & 3.81 & 12.72 \\
\hline
\end{tabular}

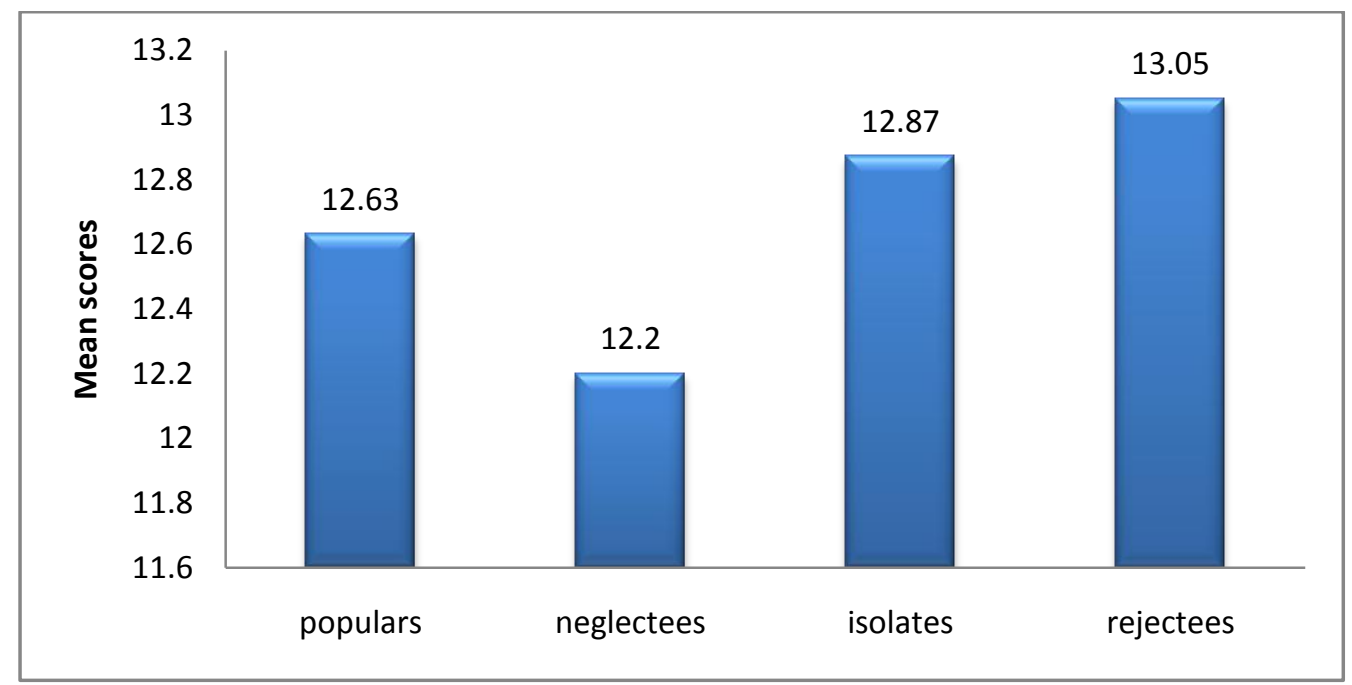

Fig. 1- Mean scores of populars, neglectees, isolates, and rejectees on the variable of Impulsiveness 
A look at table 3, shows that the mean score of populars is 12.63 and percentage mean is 42.10 , negelectees having mean score of 12.10 and percentage mean is 40.66 , isolates posses mean score of 12.87 and percentage mean 42.90 and rejectees are having mean score of 13.05 and percentage mean of 43.50. Rejectees posses highest mean on the variable of Impulsiveness.

Thus, the hypothesis second i.e., "Significant difference will be found on the variable of Impulsiveness between two sociometric groups. (i.e., populars \& neglectees, populars \& rejectees, populars \& isolates, neglectees \& isolates, neglectees \& rejectees, isolates \& rejectees)" is rejected.

\section{MAIN FINDINGS OF THE STUDY}

On the variable of Impulsiveness there was no significant difference among four Sociometric groups i.e., populars, neglectees, rejectees, isolates. Rejectees have the higher level of impulsiveness than populars, neglectees and isolates.

No Significant difference was found on the variable of Impulsiveness between two Sociometric groups. i.e., populars \& neglectees, populars \& rejectees, populars \& isolates, neglectees \& isolates, neglectees \& rejectees, isolates \& rejectees.

\section{SUGESSTIONS FOR FURTHER RESEARCH}

Findings of the present study, therefore, opens up certain avenues for further research.

- In the present research, only four sociometric groups namely the groups of populars, neglectees, rejectees, and isolates are taken up. It is suggested that research may also be done on some other sociometric groups such as groups of below average students, average students and above average students.

- The sample in the present study consisted of 100 subjects from each category taken from random selected schools of Aligarh. It is suggested that research may be tried on a larger sample, which may be taken from one or more states of the country.

- This study is based on sociometric groups of secondary school students only. It is suggested that research studies may be conducted on primary school students and senior secondary school students. The Sociometric groups are taken only from the girls, it is 
suggested that boys may also be taken up or comparison of boys and girls may be made to make study more comprehensive.

- For further researches, the researchers may take different combination of variables for the study of sociometric groups. The variables which have been taken in this study may also be use to study on other sociometric groups like above average, average, below average and cliques etc. The same variables or the combination of the same variables may be taken to study different interpersonal relationships.

\section{SUGESSTIONS FOR TEACHERS}

- Since a teacher has to deal with groups for five six periods daily, he should have adequate understanding of dynamics of groups. So that the forces of the group could be utilized for making teaching-learning process effective and for providing better guidance for adjustment.

- The teacher should encourage the populars and give them more work so that their energies could be utilized for the betterment. The quality of leadership and co-operation may be developed among them. Human leadership resources in a class can be surveyed by the teacher with the help of students, and a panel of experts can be ready to help any pupil requesting it (Fox \& Luszki, 1966).

- In this investigation, one or two isolates have been found in almost all the classes. The teacher should try to find out the causes of their isolation. The teacher may select few students from the class who show least aversion to the isolates and form occasional groups, small in size, of isolates and other promising classmates. The groups should be asked to work together on a task, in which the isolates have some hope of success. Success breeds success. Finding a measure of success, the isolates may throw some of the difference that made them unpopular. The improved morale derived from satisfactory social relationships in the classroom helps create in the students a favourable attitude towards the learning experience and towards the school (Gronlund, 1965).

- The teacher should pay proper attention on the group of isolates also. Their low general mental alertness may be one of the possible causes for their isolation. The teacher should try to find out the other causes also which make them isolated. The teacher may take the help of popular students to encourage isolates to participate in group activities so that they could consider themselves as part and parcel of the class, school \& ultimately the 
society and live as active member of the society. There are some projects or work that really require group action and involve a number of different kinds of skills. The isolates may receive much help if allowed to work with a group (Blair \& Jones, 1975).

Thus, the teacher should develop cordial and intimate social interaction within the students in order to create healthy and educative atmosphere in the class as well as in the society.

\section{REFERENCES}

Barratt, E.S. (1965). Factor analysis of some psychometric measures of impulsiveness and anxiety psychological reports $16,547-554$.

Barratt, E. S. (1994). Impulsiveness and aggression. In J. Monahan \& H. J. Steadman (Eds.), Violence and mental disorder: Developments in risk assessment (pp. 61-78). Chicago: University of Chicago Press.

Blair, G.M., Jones, R.S. \& Simpson, R.H.(1968). Educational psychology, New York, Macmillan Publishing Co.Inc., PP. 313-320.

Campbell, A. (2006). Sex differences in direct aggression: What are the psychological mediators? Aggression and Violent Behavior, 11, 237-264. doi:10.1016/j.avb.2005.09.002

Corsini,R.J. ( 1999 ). The dictionary of psychology, Psychology Press, ISBN 158391028X, pp. 476.

Eysenck,S.B. \& Eysenck,H.J. ( 1977 ). The place of impulsiveness in a dimensional system of personality description. Journal of social clinical psychology. Vol.16(1), pp.57-68.

Eysenck, S. B. J., Pearson, P. R., Easting, G., \& Allsop, J. F. (1985). Age norms for impulsiveness, venturesomeness and empathy in adults. Personality and Individual Differences, 6, 613-619.

Forsyth,D.R. (2006). Group dynamics. Wadsworth, cenage learning. U.S.A. Fifth edition. pp.No.1.

Fox, R. \& Luszki, M.B.(1966). Diagnosing classroom learning environments, Chicago. Science Research Associates.

Gronlund, N.E.(1965). Society and improved social relations in the classroom. High school Journal. Vol.48, pp. 186-203

Lorenzo-Chávez.K, Schneider.B.H, Alvarez-Valdivia.I.M, Pérez-Luján.D, Becali-Puerta.L, Sanz.Y.A. (2011). Social Reputation and Children's Adjustment in a very Collectivistic Society: A longitudinal exploration. Caribbean Journal of psychology, Cuba. Vol. 4, issue 1.

Moreno, J. L. (1934). Who shall survive? A new approach to the problem of human interrelations. Nervous and Mental Disease Monograph Series, No. 58. Washington, D.C.: Nervous and Mental Disease Publishing Co.

Malik, S. (1978). A sociometric study of personality patterns of adolescent girls as measured through free expression drawings. Unpublished M.ed. dissertation, Punjab University, Chandigarh. 
Parker, J. D. A., \& Bagby, R. M. (1997). Impulsivity in adults: A critical Review of measurement approaches. In C. D. Webster \& M. A. Jackson (Eds.), Impulsivity: Theory, assessment, and treatment (pp. 142-157). New York: Guilford Press.

Parren,S.;Vonwyl,A.;Stadelmann,S. \& Burgin,D. (2006). Association between behavioral /emotional difficulties in kindergarten children and the quality of their peer relationships. Journal of American child adolescent psychiatry. Vol.45. 867-876.

Poulin, F. \& Dishion, T.J. (2008). Methodological Issues in the Use of Peer Sociometric Nominations with Middle School Youth. Journal of Pub.Med. doi: 10.1111/j.14679507.2008.00473.x. Vol. 17(4): Page No. 908.

Rai, S.N. \& Sharma, A. (1988). Impulsiveness scale. National psychological corporation. Agra Sharma,A. (1970). Hand book on sociometry for teachers and counselors, NCERT, New Delhi, Buch survey, Vol.1.

Strüber, D., Luck, M., \& Roth, G. (2008). Sex, aggression and impulse control: An integrative account. Neurocase, 14(1), 93-121. 10.1080/13554790801992743

Wallien, S.C.; Veenstra, R.; and Cohen-Kettenis, P.T. (2009). Peer Group Status of Gender Dysphoric Children: A Sociometric Study. Journal of Pub. Med. doi: 10.1007/s10508009-9517-3. 553-560

Wilson,B.J. (2006). The entry behavior of aggressive/rejected children: The contributions of status and temperament. Social development, 15, 463-479. 